cooperation is liable to break down when threatened by outsiders, especially if they speak another language? McGoodwin himself says "Local fishers will indeed stop fishing with restraint when newcomers invade their property." If this is so, how do we construct cooperative management systems that will stand the test of time?

It is regrettable that $\mathrm{McGoodwin}$ makes such a point of condemning the attempts made so far by fisheries' managers to find solutions to the perennial and intractable problem of the rational and equitable exploitation of fisheries. It leaves one ill-disposed towards the remainder of his thesis, especially as this is presented with a gloss of New Age optimism, which implies that here at last is the missing ingredient we have all been seeking. In fact, what he proposes is that attempts to regulate fisheries should take more account of the social problems of those involved (mainly the fishermen), should try to work through cooperation and self-regulation, and should involve the fishermen more intimately in the setting of regulations and the formulation of policies. This is not new, indeed ICES has for many years been organizing so-called 'dialogue meetings' of fishermen's representatives, biologists, economists and administrators, precisely to try to make progress along these lines, with only modest success. Nevertheless, most people involved agree that we need to move in this direction, and another reminder would do no harm. Unfortunately, this reminder will annoy the converted, and is unlikely to persuade the rest.

McGoodwin bemoans the fact that fisheries management agencies employ so few sociologists and anthropologists. If Crisis in the World's Fisheries is a fair example of what they can do for us, I doubt that that will change.

John Shepherd is at the Ministry of Agriculture, Fisheries and Food, Fisheries Laboratory, Pakefield Road, Lowestoft, SuffolkNR33 OHT, UK.

\section{Language and lexicography}

\section{Paul Fletcher}

The Science of Words. By George Miller. W. H. Freeman \& Co.: 1991. Pp.276. £10.95, \$12.95.

IN the popular view, the science of words is enshrined in lexicography. And the rich tradition of dictionary-making in English, from before Dr Johnson to Dr Burghfield, is acknowledged not only at various places in George Miller's text, but in his current project, WordNet. This involves the development of a dictionary of English, accessible on-line, whose lexical database is organized on the basis of current psycholinguistic theories.

Conventional dictionaries provide information primarily about the meaning of a word, along with its pronunciation and spelling, and the syntactic category to which it belongs. This, as Miller points out, is a good start. Any theory of the mental lexicon, of how the individual organizes and accesses his store of words in memory, will begin from this form-meaning association. But it must also take account of the networks of relationships, of both form and meaning, that relate individual words. Speakers know, or learn, that a pit-bull terrier is a kind of dog, that leaping is a particular way of jumping, that tall people are at the upper end of a scale of height and short people at the lower end, that there is a similarity in meaning between 'book' and 'monograph'. In addition to these meaning relationships (respectively hyponymy, troponymy, antonymy and synonymy), speakers also know about relationships of form. Writers write, and researchers research, but porters do not port.
Parliament recesses, but a recession is something different, even though there does seem to be a meaning-preserving derivational relationship between the verb 'process' and the noun 'procession'.

It is Miller's career-long involvement with the representations of words and their form and meaning relationships in the minds of speakers that informs and shapes this book. He systematically examines the three-sided character of words identified by the lexicographer - spoken/written form, syntactic role and concept - from the perspective of the mental lexicon. As is appropriate for a general, introductory text, this involves some exposition of the development and current status of writing systems, of the physics of speech and the structure of phonologies in languages, and of how the syntax of sentences is organized. These accounts of how words are pronounced or written, and how they are organized into permissible linear sequences are never less than lucid, elegantly written and, most remarkable to someone familiar with the standard, visually drab linguistics text, lavishly and imaginatively illustrated. But these sections serve as background for Miller's main interest, the words themselves. How words evolve, how many we know, how they are learned, the nature of their storage and retrieval, lexical loss through brain damage, the boundaries between linguistic and encyclopaedic knowledge are some of the topics that Miller deals with. In a synthesis of his own work (for he is a contributor of the first rank to this field) and other research, he writes in a style which is clear, while eschewing superficiality.

Some of the most interesting current work on the mental lexicon concerns its acquisition by children. Miller enjoins us to be sceptical about estimates of vocabulary size but, that done, suggests a possible vocabulary size for the average US high-school graduate of 60,000 root words. Assuming these are acquired over 16 years, this suggests (if we allow another assumption, of a constant rate of acquisition) something over ten new words a day. Because, at least in the early stages of language development, the only information available to the pre-literate child about the form of a word is through the auditory channel, we need to consider an acquisition device that can assemble the sound-meaning relationships embodied in words with some facility.

Recent work, reviewed by Miller, shows that there is, for the learning of a word, an initial 'fast mapping' phase. In one experiment, three-year-old children were presented just once with the presumably unfamiliar word 'chromium' to refer to an object that was olive-green. A week later, when tested, half of them could recognize the word (that is, had remembered its phonetic shape) and knew it was a colour word. They could assign the unfamiliar term to the semantic field of colour names, even though they were unable to identify the colour precisely. Following the initial acquisition of phonetic form and some meaning information, there is a slower second phase, which may require many more instances of the particular word for its syntactic role and full meaning to become clear for the child. Different syntactic categories have been investigated, and it appears that for fast mapping, verbs cause children more difficulties than nouns. Although Miller does not deal directly with this issue, reasons for the discrepancy between nouns and verbs in acquisition can be derived from a discourse on semantic relations between verbs, which is unusual for a general text in being quite original.

For a general text on the science of words and their users, which can be said to be introductory but which is also lucid, interesting and original, look no further. It deserves to be popular.

Paul Fletcher is in the Department of Linguistic Science, University of Reading, $P O$ Box 218, Reading RG6 2AA, UK.

\section{New in paperback}

- Cosmos: The Growth of Order in the Universe by David Layzer provides a highly individualistic analysis of cosmology, start ing with subatomic particles and ending up with the evolution of the human mind. Published by Oxford University Press, price is £8.95.

- Many scientists have difficulties deciding how best to present their findings for the purposes of publication; Writing Successfully in Science by Maeve O'Connor should reduce the pain. Published by Harper Collins at $£ 8.95$ (aiso available in hardback, price $£ 25$ ).

All those with an interest in ornithology or the evolution of animal behaviour should find something to their liking in Behavior and Evolution of Birds, edited by Douglas Mock. The book is a collection of articles from Scientific American and is published by Freeman at $\$ 12.95$. 